ARTIGOS

\title{
As possibilidades de uma experiência compartilhada entre adultos e crianças na cidade
}

\section{The possibilities of a shared experience between adults and children in the city}

Vania Carvalho de Araújo (i) José Sérgio Fonseca de Carvalho (ii)

(i) Universidade Federal do Espírito Santo - UFES, Vitória, ES, Brasil, vcaraujoufes@gmail.com.

(ii) Universidade de São Paulo - USP, São Paulo, SP, Brasil, jsfcusp@usp.br.

Resumo: Este artigo coloca em evidência os constrangimentos de uma sociedade, cuja intensificação dos processos de destruição da cultura pública, mediada pela erosão da convivialidade humana, determina os limites da existência comum. A “crise na educação", descrita por Arendt (2007), parece transpor-se à crise na cidade, quando a exagerada preocupação com a proteção e a autonomia das crianças subtrai a arte do com-viver e do bem-viver. Discorrer sobre a perda do mundo comum, como um modo de problematizar a experiência entre adultos e crianças na cidade, é uma reflexão importante a trilhar, principalmente quando a extensão dos critérios utilitaristas da vida desafia a recobrar a amizade e a hospitalidade como uma atitude importante diante da criança "estrangeira" que precisa ser acolhida.

Palavras-chave: crianças e adultos na cidade, cidade, Hannah Arendt, relação criança-adulto

Abstract: This article bighlights the constraints of a society whose processes of public culture destruction mediated by the erosion of human conviviality determine the boundaries of common existence. The "education crisis" described by Arendt (2007) seems to be transposed to the crisis in the city, when the exaggerated concern about children's protection and autonomy deprives them from the art of living with and living well. Discussing the loss of the common world as a means of problematizing the experience between adults and children in the city is an important idea to be addressed, especially when the extension of the utilitarianist criteria of life challenges us to reinstate friendship and hospitality as important attitudes when facing the "foreign" child that needs to be welcomed.

Keywords: children and adults in the city, city, Hannah Arendt, adult-child relationship 


\section{pro.posıções}

http://dx.doi.org/10.1590/1980-6248-2016-0021

\section{$e$-ISSN 1980-6248}

\section{Notas (ou questões) introdutórias}

$\mathrm{Na}$ contemporaneidade, somos cada vez mais impelidos a nos afastar da cidade, um território traduzido como um aglomerado de preocupações privadas e tempos socialmente demarcados. Por ser espaço tradutor de uma ordem social, cujas referências têm nos transformado em atônitos transeuntes de uma espacialidade configurada pela segregação e pelos constrangimentos que desertificam cada vez mais as possibilidades de uma experiência compartilhada, da cidade resta-nos proteger dos riscos e dos interditos, conservando nossas intimidades e propagando nossas incivilidades mediadas por interesses privados.

Se os efeitos de uma narratividade urbana fragmentada já são notórios em nosso cotidiano, inscrever outras formas discursivas e práticas torna-se uma tarefa desafiadora, principalmente em dinâmicas societárias em que as fronteiras entre o público e o privado estão bem demarcadas, e a constante destruição produzida pela ordem capitalista de uma esfera pública compartilhada aparece como recurso psicológico e social para uma suposta "reinvenção" da cidade. "A passagem da economia de mercado para uma sociedade de mercado, tal como ocorre no crescimento da cidade, destrói as formas de experiência de espaço e de tempo públicos, tudo determinado diretamente pela economia” (Matos, 2009b, p. 76).

Em sua densa discussão sobre os efeitos da privatização da existência, perpetrados pela moderna sociedade industrial do século XIX, Sennett (1988) destaca as contradições da vida comunitária moderna, quando as pessoas, ao mesmo tempo em são emocionalmente abertas umas com as outras, são vigilantes umas com as outras. $\mathrm{O}$ resultado dessa aparente vida comunal e desse exercício de fraternidade frequentemente se transforma em uma "experiência de fratricídio" (p. 366). Sennett (1988) assim define a cidade e a civilidade na vida moderna:

Civilidade é tratar os outros como se fossem estranhos que forjam um laço social sobre essa distância social. A cidade é esse estabelecimento humano no qual os estranhos devem provavelmente se encontrar. A geografia pública de uma cidade é a institucionalização da civilidade. (pp.323-324)

Estaríamos cada vez mais fadados à intensificação dos processos de destruição da cultura pública, da erosão da convivialidade humana e da arte do com-viver e do bem-viver na cidade ou seria possível arriscar a pensar a cidade como espaço público de coexistência, inscrevendo outras possibilidades éticas e estéticas de existência e de coabitação cidadã, 


\section{pro.posıções}

$e$-ISSN 1980-6248

http://dx.doi.org/10.1590/1980-6248-2016-0021

transformando a cidade em um espaço de objetivos e significações partilhadas? Se tudo isso requer um modo peculiar de lidar com as hostilidades que desestabilizam as nossas esperanças, percorrer outros caminhos mais próximos dos desvios e dos riscos do que das certezas que a própria realidade nos impõe, certamente, é uma trajetória menos segura pelo desafio que ela comporta, mas mobilizadora de um outro tipo de experiência entre adultos e crianças na cidade.

Se, para os adultos, a evidência de uma cidade fraturada e atomizada por um urbano institucionalizado pelas contingências do mercado determina os limites e as referências de uma existência socioespacial, para as novas gerações acentua-se o caráter disciplinador da cidade, restringindo sua circulação a espaços demarcados por discursividades cerceadoras de um mundo compartilhado.

Mediante a novidade que se impõe como verdade absoluta e a ascensão da esfera privada, em que as pessoas são obrigadas a viver à margem do mundo comum, as crianças são ameaçadas de esquecimento, fixadas à natureza mesma de sua existência, separadas que estão do convívio com os adultos. Além disso, outras ordens interceptam a educação das crianças na cidade, impedindo-as de se apropriarem de um mundo comum de heranças simbólicas e materiais. Para Arendt (2007), a falta de responsabilidade pelo mundo, decorrente da atitude dos adultos, traz como consequência uma exagerada preocupação de instruir as crianças "na arte de viver, como se a infância fosse um estado humano autônomo, capaz de viver por suas próprias leis" (p. 246). Assim, "sob o pretexto de respeitar a independência da criança, ela é excluída do mundo dos adultos e mantida artificialmente no seu próprio mundo, na medida em que este pode ser chamado de um mundo" (p. 233)

É o que podemos observar quando na cidade moderna a interdição dos espaços e a institucionalização de seus usos demarcam o caráter disciplinador de sua ocupação, separando os indivíduos segundo sua condição de classe, etnia e pertença a um grupo etário; todos reféns de sua mera diferenciação.

O nosso mal-estar urbano está levando ao que alguns autores já estão chamando de uma era da segurança, [ênfase no original] o que em termos da vida urbana contemporânea nos empurra a ter que optar entre a cidade aberta ou a cidade fechada. (Kuster \& Pechman, 2007, p.596)

Assim, a cidade repartida cria nichos de uma exposição privada onde não é possível trocas materiais e simbólicas entre adultos e crianças, ora porque sua materialização funciona 


\section{pro.posıções}

$e$-ISSN 1980-6248

http://dx.doi.org/10.1590/1980-6248-2016-0021

em nome da segurança e da vigilância, ora porque a polis, como comunidade política e organização mais elevada do convívio humano, perdeu o seu sentido ao longo dos séculos e deixou de se mostrar uma referência importante para pensarmos a nossa experiência em comunidade na contemporaneidade e superarmos os "processos de desertificação" que insistem em expandir, destruindo tudo o que há de comum entre nós.

Referindo-se ao mundo como um artifício humano, um legado material e simbólico, cuja duração transcende a vida de homens mortais, afirma Arendt (2010): "Se o mundo deve conter um espaço público, não pode ser construído apenas para uma geração e planejado somente para os que estão vivos, mas tem de transcender a duração da vida de homens mortais" (p.67). Isso explica a peculiar preocupação da autora com a educação das crianças que vai além do desenvolvimento das competências pedagógicas e da autonomia delas.

$\mathrm{Na}$ medida em que a criança não tem familiaridade com o mundo, deve-se introduzi-la aos poucos a ele; na medida em que ela é nova, deve-se cuidar para que essa coisa nova chegue à fruição em relação ao mundo como ele é. Em todo caso, todavia, o educador está aqui em relação ao jovem como representante de um mundo pelo qual deve assumir a responsabilidade, embora não o tenha feito e ainda que secreta ou abertamente possa querer que ele fosse diferente do que é. Essa responsabilidade não é imposta arbitrariamente aos educadores; ela está implícita no fato de que os jovens são introduzidos por adultos em um mundo em contínua mudança. Qualquer pessoa que se recuse a assumir a responsabilidade coletiva pelo mundo não deveria ter crianças, e é preciso proibi-la de tomar parte em sua educação. (Arendt, 2007, p. 239)

Essa responsabilidade pelo mundo, de acordo com Arendt, assume a forma de autoridade, e a perda da autoridade no âmbito da educação diz respeito à recusa da responsabilidade dos adultos em orientar as crianças no mundo, tendo como princípio o legado das heranças simbólicas públicas. Para Arendt (2007), a crise na educação, corresponde à ausência da autoridade no seu âmbito. "A crise da autoridade na educação guarda a mais estreita conexão com a crise da tradição, ou seja, com a crise de nossa atitude face ao âmbito do passado" (p. 243).

Há nas reflexões de Arendt sobre "a crise na educação" um compromisso com o mundo comum. Se a educação deixa de apresentar às crianças as heranças simbólicas do passado, ela não só deixa de assumir a responsabilidade pelo mundo, mas tampouco leva a cabo a tarefa de ajudá-las a renovar o mundo comum. Daí porque Arendt (2007) afirma que, na educação, "essa responsabilidade pelo mundo assume a forma de autoridade" (p.239), isto é, o compromisso de apresentar o mundo às crianças para que elas possam criar novos mundos. Do contrário, 


\section{pro.posıções}

$e$-ISSN 1980-6248

http://dx.doi.org/10.1590/1980-6248-2016-0021

teríamos, como resultado, os efeitos peculiares a uma sociedade de massas, uma sociedade "composta por indivíduos isolados que não tomam decisões sobre o mundo nem assumem responsabilidade por ele, mas apenas funcionam no grande processo de produção e consumo" (Almeida, 2011, p. 49). É nesse sentido que Arendt diz que não estamos apenas "no mundo", mas "somos do mundo", o que implica em uma responsabilidade pessoal que "visa a um novo simbolismo cultural que interpela alteridade, visibilidade e mundo comum" (Assy, 2015, p. xxxiii).

Dos efeitos da recusa da autoridade na educação das crianças aos pretextos de mantêlas artificialmente no seu próprio mundo, outras questões necessitam ser elucidadas, principalmente quando identificamos que, na exterioridade reveladora da cidade e na maneira de o espaço urbano atua como mercadoria e impessoalidade, há mais do que a simples imagem de um presente angustiante, solapado por violência, indiferenças, pobreza, solidão, trabalho, etc., mas um estranhamento do mundo que nos torna incapazes de criar uma experiência pública compartilhada, voltados que estamos para a “interioridade do self” (Assy, 2004).

Discorrer sobre a perda do mundo comum, conforme destaca Arendt (2010), como um modo de problematizar as possibilidades ou não de uma experiência compartilhada entre adultos e crianças na cidade contemporânea, parece-nos uma reflexão importante a trilhar. Para Arendt (2010),

o que torna a sociedade de massas tão difícil de ser suportada não é o número de pessoas envolvido, ou ao menos não fundamentalmente, mas o fato de que o mundo entre elas perdeu seu poder de congregá-la, relacioná-las e separá-las. (p. 64)

As perplexidades impostas pela modernidade, com a desertificação e o desmoronamento do mundo humano e a extensão dos critérios utilitaristas e pragmáticos da vida produziram relações cuja "temporalidade é a do efêmero, do descartável” (Matos, 2006, p. 155).

O que há de comum entre a responsabilidade e a autoridade? Ambas se comprometem com o mundo comum, mas esse mundo comum, ressalta Arendt (2010),

só pode sobreviver ao vir e ir das gerações na medida em que aparece em público. É a publicidade do domínio público que pode absorver e fazer brilhar por séculos tudo o que os homens venham a querer preservar da ruína natural do tempo. (p.67) 


\section{pro.posıções}

http://dx.doi.org/10.1590/1980-6248-2016-0021

$e$-ISSN 1980-6248

Talvez esteja aí a chave para pensarmos de que maneira a fruição de um mundo comum e a necessária - embora móvel - distinção entre os assuntos públicos e os interesses privados, condição política da polis, podem nos ajudar a compreender a "crise na cidade", a qual parece guardar estreita relação com a "crise na educação" - entendida como "ausência de significações partilhadas por uma comunidade", não só pela despolitização da cidade como espaço público, mas pela busca contínua e desenfreada da reificação do novo, por uma "temporalidade aderida à aceleração do presente" (Matos, 2009a, p. 92), pela tentativa de "preparar" as novas gerações para um futuro promissor e pela exclusão da criança do mundo dos adultos. "Uma das manifestações mais claras da crise é, para Arendt, a perda do senso comum, entendido não em sua acepção corrente de oposição a um saber científico, mas como a ausência de significações partilhadas por uma comunidade" (Carvalho, 2013, p. 19).

Numa sociedade fragmentada como a nossa, voltada à presentificação da vida, onde "o público foi despojado de seus conteúdos diferenciais e ficou sem agenda própria - não passa agora de um aglomerado de problemas e preocupações privados” (Bauman, 2000, p. 71), assumir a responsabilidade pelo mundo e apresentar às crianças o legado de heranças simbólicas de um mundo preexistente ao seu nascimento certamente é um desafio um tanto complexo.

A constatação de Arendt acerca dos efeitos da ausência de responsabilidade pelo mundo e da autoridade dos adultos diante das crianças traz uma atualidade ímpar de seu pensamento, sobretudo quando a "crise na cidade" parece dizer respeito ao lugar que a tradição com o seu legado de realizações históricas e a responsabilidade pelo mundo comum têm ocupado na contemporaneidade. O âmbito da necessidade e do consumo, a despeito de uma experiência pública compartilhada, parece constituir-se um dos maiores constrangimentos em nossas cidades, onde todos devem se "dobrar ao jogo da circulação infinita e expandida da mercadoria" (Dany-Dufour, 2005, p. 13). Para Matos (2009b), “as metrópoles encontram-se em constante e acelerada transformação, o que resulta no desaparecimento dos suportes objetivos da memória" (p. 75), cujo efeito é a perda de um passado que deixou de ser tradição.

A capacidade argumentativa e interpretativa de Arendt sobre uma época, cujo legado do passado foi subvertido e colocado em segundo plano em função da tecnificação da vida e da produção de novos fenômenos de alienação e estranhamento do homem em relação ao mundo, faz-nos confirmar a atualidade de seu pensamento, principalmente quando observamos a deterioração da esfera pública por critérios que regem a esfera privada, e a cidade, tal qual o 


\section{pro.posições}

$e$-ISSN 1980-6248

http://dx.doi.org/10.1590/1980-6248-2016-0021

mito bíblico de Babel, se espraia como caos urbano original, uma vez que "sua construção indica centramento, desafio do homem que se eleva desmesuradamente, esquecendo-lhe de que lhe é impossível ultrapassar a sua condição humana. ... Sua destruição aponta para o desvio, a dificuldade de comunicar" (Gomes, 2008, p. 87).

Incorporando os automatismos do mercado de consumo, a cidade volta-se à superfluidade da vida e às contingências do capitalismo desmedido, impossibilitando-nos, assim, de criar um mundo comum a todos e laços mais duradouros. "A destruição dos espaços da cidade converte-a em metrópole impessoal e sem memória. ... Tudo é repetição, é multiplicação do sempre igual” (Matos, 2009b, p. 75). Assim, "o mundo deixa de ser um artifício comum a compartilhar entre gerações para, também ele, ser consumido [ênfase no original] no presente" (Carvalho, 2013, p. 81).

Essa frequente produção de incivilidades tem produzido efeitos avassaladores em relação ao nosso modo de habitar a cidade em companhia das crianças. A destituição do mundo como um artifício humano material e simbólico parece constituir-se o nosso maior esforço de reflexão sobre a cidade e a possibilidade de a felicidade pública, a hospitalidade e a amizade se desvelarem como arte do com-viver e do bem-viver.

Esse esforço se coloca, tendo em vista duas perspectivas a orientar as nossas reflexões seguintes. A primeira volta-se à suplantação do "olhar do espanto" pelas perplexidades do nosso tempo. Utilizamos a expressão "espanto" (thaumadžein) - a marca dialogal da filosofia - como um esforço analítico para pensar os efeitos ameaçadores e desconcertantes da modernidade e a possibilidade de uma dimensão ético-política que aproxime a cidade contemporânea da polis, ao menos naquilo que seu legado nos transmite - preocupação com o bem-comum, suporte de criação de uma cultura política na cidade. A polis grega como uma forma elevada de convívio humano, nesse caso, não é vista como algo que ficou no passado, mas uma referência importante de pensar o desmoramento do mundo humano e a possibilidade da cidade como espaço público, espaço no qual a ação e a palavra de cada um podem ser reconhecidas na construção de um mundo compartilhado.

Outra perspectiva de reflexão aponta a responsabilidade pelo mundo como possibilidade de uma educação que torne as crianças capazes de se familiarizar em um mundo preexistente e, assim, renovar o mundo. O horizonte dessa formação está na significação da 


\section{pro.posıções}

$e$-ISSN 1980-6248

http://dx.doi.org/10.1590/1980-6248-2016-0021

felicidade pública tradutora da amizade, da concórdia e da hospitalidade como dimensão da convivência humana que atravessa a experiência entre adultos e crianças na cidade.

Se com a modernidade a cidade se transforma, cada vez mais, em um espaço ameaçador dos encontros e da experiência, outras possibilidades se colocam como reveladoras de uma cultura pública em que a existência seja mais do que a multiplicação de solidões; e a cidade, uma mixórdia de eventos e acontecimentos.

\section{A perda do "espanto" e as perplexidades de nosso olhar sobre e na}

\section{cidade}

O espanto (thaumádzein) é o que fez surgir a filosofia grega, a marca dialogal com o mundo, onde a perplexidade, o assombro, o maravilhar-se com o mundo e a admiração permitiam pensar o mundo e indagar sobre a realidade, evitando, como afirma Arendt (2008), “o dogmatismo dos meros detentores de opiniões" (p.81). O conhecimento nasce do espanto, quando o ser humano se assombra com o mundo ameaçador e desconcertante e indaga sobre a realidade. Tal como a atividade socrática de pensar, o espanto é uma atividade que desestabiliza padrões e conceitos já dados e ativa novas formas de reflexão a partir de um diálogo comigo mesmo.

O primeiro atributo do pensar é o espanto, provocar perplexidade, paralisar e interromper argumentos tidos como dados, particularmente a respeito de conceitos gerais como justiça, coragem e felicidade, que ganham outra intensidade quando suas descrições se atrelam obrigatoriamente às experiências concretas. (Assy, 2015, p. 66)

Se, na modernidade, a presentificação da vida e seus incessantes agoras deixam escapar os princípios orientadores de nosso ser e estar no mundo, desfazendo-nos dos testemunhos do passado e dos critérios com os quais nos orientávamos para assim adequarmos mais "livremente" às promessas do consumo e da superfluidade do humano, o "olhar de espanto" parece suplantar-se pelo olhar de um futuro imprevisível e inquestionável. Essa afirmação está associada à nossa incapacidade de formar julgamentos sobre o mundo com o desmoronamento do mundo humano na modernidade, caracterizado pela destruição do espaço que nos permite ser humanos. Arendt, por sua vez, enfatiza um tempo de esvaziamento da dignidade da política, 


\section{pro.posições}

$e$-ISSN 1980-6248

http://dx.doi.org/10.1590/1980-6248-2016-0021

traduzido como a drástica ruptura com os fundamentos e as garantias que, antes, a religião, a tradição e a autoridade podiam oferecer como capacidade de discernimento e de escolhas entre o bem e o mal, a verdade e a mentira, o justo e o injusto. Com a perda de tais critérios, o que nos resta é o pensar, entendido como capacidade de examinar e refletir sobre tudo aquilo que vem a acontecer, colocando em questão todas as certezas, de modo a compreender melhor nossa experiência no mundo.

A despolitização do mundo e a ascensão da privatividade no mundo moderno colocaram em evidência a destruição não só da singularidade, mas da pluralidade, o "estar entre os homens", aquela atividade humana de agir em conjunto, tendo em vista a construção de um mundo compartilhado. Para representar essa crescente perda do mundo comum, Arendt (2010) utiliza-se da metáfora do deserto como ausência da experiência pública compartilhada, ausência de espaços comuns entre nós.

Compreendendo a história como registro das iniciativas humanas, Arendt (2008) aposta na possibilidade de reconciliação com o mundo, quando partilhamos nossas experiências com vistas ao bem comum. Inspira-se na capacidade humana de perdoar, já que o perdão, uma novidade especificamente política, diferente da religiosa, "busca o aparentemente impossível, desfazer o que foi feito, e ele consegue forjar um novo começo onde começos já não parecem possíveis" (p. 105). O grande milagre do mundo estaria nessa improbabilidade infinita de perdoar e, com Agostinho, difere principium (que corresponde ao começo do universo) de initium (que é o homem como ser que age). O perdão, afirma Arendt (2008),

é a única ação estritamente humana que liberta a nós e aos outros da cadeia e padrão de consequências que toda ação humana engendra; como tal, o perdão é uma ação que garante a continuidade da capacidade de agir, de começar de novo, a todo ser humano; sem perdoar e ser perdoado, nos pareceríamos com os personagens de contos de fada que são eternamente castigados com a realização dos desejos que lhes são concedidos. (p. 106)

Estaríamos dispostos a perdoar e iniciar algo novo no emaranhado de existências que atravessam o nosso modo de habitar a cidade? Se os efeitos da violência, da "banalidade do mal", do apelo ao consumo, da fugacidade do tempo, da ordem das urgências, da perda da tradição e da autoridade conformam a materialidade da cidade na contemporaneidade, ainda é possível pensar a cidade como espaço público diante da politização do privado, herança identitária da modernidade, cujos efeitos produziram a perda da experiência conforme bem 


\section{pro.posıções}

$e$-ISSN 1980-6248

http://dx.doi.org/10.1590/1980-6248-2016-0021

demonstra Walter Benjamin (2012), ao retratar o que se passava na Alemanha sob os efeitos da modernidade: "A liberdade da conversa está-se perdendo. Se antes, entre seres humanos em conversa, a consideração pelo parceiro era natural, ela é agora substituída pela pergunta sobre o preço de seus sapatos ou de seu guarda-chuva" (pp.21-22). Ao invés do "olhar de espanto", temos um olhar rotineiro diante dos acontecimentos na e da cidade que não nos evoca além daquilo que ele aparenta ser.

Esse olhar de perplexidade diante de uma temporalidade marcada pela ordem do efêmero, do fugaz e do obsoleto, em que o passado deixou de iluminar o presente em um mundo moderno atravessado por riscos e incertezas, foi também pressentido por Bertolt Brecht em seu poema “Aos que vierem depois de nós” (Tradução de Manuel Bandeira).

Realmente, vivemos muito sombrios!

A inocência é loucura. Uma fronte sem rugas

denota insensibilidade. Aquele que ri

ainda não recebeu a terrível notícia

que está para chegar.

Que tempos são estes, em que

é quase um delito

falar de coisas inocentes.

Pois implica silenciar tantos horrores!

Esse que cruza tranquilamente a rua

não poderá jamais ser encontrado

pelos amigos que precisam de ajuda?

Se Brecht fala de um tempo, cuja barbárie da guerra expõe a face mais cruel e visível da dominação de mentes, corpos, sensibilidades, falamos de um tempo atravessado pelas incertezas do futuro, pela superfluidade do presente e pela recusa do passado como referência e orientação no mundo. Isso remete às formas como as cidades contemporâneas se mostram como prolongamento do privado, de uma interioridade não compartilhada. 


\section{pro.posıções}

$e$-ISSN 1980-6248

http://dx.doi.org/10.1590/1980-6248-2016-0021

A possibilidade da cidade como um espaço público compartilhado, uma comunidade de pertença, uma designação fundamental para o convívio humano se revela na contramão das racionalidades privadas, da "ausência de mundanidade", conforme Arendt (1987, p. 21), das evidências da "pluralidade de solidões", como bem destacara Jean-Paul Sartre (2002) ou da "ideologia da intimidade" ou "reinado da intimidade", segundo afirmara Sennett (1988), como efeitos da demonstração não pública da cidade; portanto, da multiplicação dos indivíduos à sua mera elementariedade, privados que são de "ver e ouvir os outros e privados de ser visto e ouvidos por eles" (Arendt, 2010, p. 71). Daí porque Arendt (2002) afirma que "só pode haver homem na verdadeira acepção onde existe mundo, e só pode haver mundo no verdadeiro sentido onde a pluralidade do gênero humano seja mais do quer a simples multiplicação de uma espécie" (p. 109).

A experiência fundadora da polis nos coloca diante de uma ética e de uma estética de existência cuja capacidade de diálogo entre os homens deixa transparecer a responsabilidade que eles têm pelo mundo e o uso da palavra como elemento persuasivo de mediação de conflitos. O espaço público transforma-se, assim, no espaço da visibilidade e da deliberação conjunta, onde a livre retirada do homem da vida privada (idion) e da sua entrada na vida que lhe é comum (koinon) constitui uma forma excelsa de amor pela cidade que os gregos chamaram de demos. "Nela, a isegoria significou o direito igual a todos de tomar palavra na ágora, de tornar manifestos pensamentos sem que nada permanecesse no plano oculto das segundas intenções" (Matos, 2009b, p. 63).

Para a polis, o sustento da vida e a defesa não eram o ponto central da vida política, e só eram políticos no verdadeiro sentido desde que as conclusões sobre eles não fossem decretadas de cima para baixo, mas sim se concebidas em comum no conversar de um com o outro e no convencer mútuo. (Arendt, 2002, p.66)

O apreço pelo bem comum que é a cidade tinha por pressuposto a faculdade específica do homem de falar e de expor as suas ideias de modo a que os assuntos da cidade fossem discutidos conjuntamente e os conflitos dirimidos por meio da persuasão, isto é, do convencimento que se dá entre iguais. Enquanto asty significa a cidade em seus aspectos materiais, polis é seu ethos, sua morada, seu caráter e sua maneira de ser, assim, ethos está em relação com a philia (amizade), laço afetivo pelo qual a polis se reúne (Matos, 2006). 


\section{pro.posıções}

$e$-ISSN 1980-6248

http://dx.doi.org/10.1590/1980-6248-2016-0021

Aristóteles (2009), na Ética a Nicômaco, além de situar a amizade como um consentimento, afirma que o amigo é aquele com quem compartilhamos as nossas dores e alegrias. Para Aristóteles, a concórdia envolve um sentimento de amizade embora não seja unanimidade, a concórdia só existe quando há uma coincidência de propósitos, e cada um deseja a mesma coisa para o outro.

A concórdia parece ... um certo laço de amizade que une os cidadãos em torno de determinado objetivo, a saber, dos seus interesses comuns e das coisas concernentes à vida de todos os dias. A concórdia assim caracterizada existe entre as pessoas de bem, pois concordam consigo próprios no seu íntimo e uns com os outros, na medida em que, se assim se pode dizer, existem assentes sobre si próprios (os seus desejos permanecem e não fluem e refluem como a maré em Euripo), desejam o que é justo e o que é de interesse comum, e é, portanto, para esses objetivos que se lançam em conjunto. (pp. 207-208)

Ao contrário de ser uma condição da alma, um "amor platônico”, em Aristóteles philia corresponde a uma atividade filosófica, expressão de uma atitude moral e intelectual. Essa "desafetivação" e a ênfase no seu aspecto racional, destaca Ortega (2002),

permite $[\mathrm{m}]$ sublinhar a ligação da philia com a excelência moral e sua importância para a vida boa (eudaimonia), bem como ampliar a gramática da philia, estendida quase à totalidade das relações humanas, e fazer uma forte ligação com a política e a justiça, no seu enfoque da amizade civil ou política (politike philia). (p. 38)

A amizade em Aristóteles constitui, assim, expressão de uma atitude de amor pela cidade que experiencia a arte de com-viver como fundamento para o bem-viver, e cujos esforços conjuntos tendem à felicidade pública. Enquanto philia era a amizade entre os cidadãos, philantropia significava para os gregos "amor dos homens, presteza em partilhar o mundo com outros homens" (Arendt, 1987, p. 31).

A experiência ética e política da polis grega como a forma mais elevada do convívio humano já não é possível tomar como modelo de vida em sociedade. Contudo, longe de traduzila como nostalgia a um acontecimento do passado, Arendt considera uma referência importante para pensar o mundo de hoje, mundo esse onde a asty (mercado) se sobrepõe à ágora (praça pública) (Brayner, 2008). Para Arendt, os efeitos trazidos pela modernidade tecnológica e científica produziram um processo de "desmundialização", ou seja, a perda do aspecto público do mundo, onde os homens por meio de ação e palavras se faziam conhecer e assim deliberavam conjuntamente sobre os destinos da cidade. 


\section{pro.posıções}

$e$-ISSN 1980-6248

http://dx.doi.org/10.1590/1980-6248-2016-0021

Tais reflexões dizem muito do esforço de Arendt em distanciar o sentido do espaço público do Estado, dos partidos políticos ou de quaisquer outras formas normalmente instituídas pela modernidade, incluindo-se aí os mecanismos utilizados com a tecnificação e a burocratização da vida. Somente por meio da consistência de nossas ações é possível ter responsabilidade pelo mundo e estabelecer com ele um comprometimento mais duradouro. $\mathrm{O}$ mundo comum, sublinha Arendt (2010),

é aquilo que adentramos ao nascer e que deixamos para trás quando morremos. Transcende a duração de nossa vida tanto no passado quanto no futuro, preexistia à nossa chegada e sobreviverá à nossa breve permanência nele. É isso o que temos em comum não só com aqueles que vivem conosco, mas também com aqueles que aqui estiveram antes e com aqueles que virão depois de nós. (p. 67)

Arendt reúne aqui três elementos fundamentais acerca do mundo comum. Primeiro, o caráter de permanência/durabilidade e transcendência/contingência do mundo que permitirá às novas gerações inaugurar novos mundos, tendo como referência o legado simbólico e material deixado por gerações passadas e a possibilidade de criação de novas formas de pensamento (entendido como experiência do pensar) e de sociabilidade. Segundo, a responsabilidade pelo mundo, que tem a ver com os nossos deveres para com o mundo que partilhamos e para com a comunidade a que pertencemos. Terceiro, a autoridade como uma referência ético-política de apresentar o mundo às novas gerações e ensiná-las como o mundo é. Por isso, Arendt (2007) sublinha que "a educação é o ponto em que decidimos se amamos o mundo o bastante para assumirmos a responsabilidade por ele" (p. 247).

Se, por um lado, tais reflexões colocam em questão os efeitos da modernidade produzindo a cidade impessoal, forjando a segregação dos espaços e reproduzindo a ordem do necessário e da necessidade, expõem também a possibilidade de pensar a cidade como um espaço público da cidadania e da coexistência das diferenças, uma experiência que privilegia laços mais perenes entre adultos e crianças. Contudo, aproximar a cidade contemporânea de formas mais elevadas de convivência humana implica em recuperar a sua dignidade, que é a de viver juntos; recuperar a sua memória, que significa recobrar os vínculos éticos e morais que nos orientavam no mundo; reaver o seu sentido, que é de uma felicidade pública mobilizada por significações partilhadas entre as gerações, transgressora de qualquer tentativa de privatização do espaço público. 


\section{pro.posıções}

$e$-ISSN 1980-6248

http://dx.doi.org/10.1590/1980-6248-2016-0021

Se a perda da amizade e a ausência de uma disposição para compartilhar o mundo a despeito das diferenças fizeram surgir um tipo de institucionalização e formalização de convivência da e na cidade, essa questão nos chama a atenção para a literal sentença de reclusão e confinamento dada às crianças, quando mantidas artificialmente em seu próprio mundo e excluídas do mundo dos adultos. Em nome da autonomia do mundo da criança, espaços especializados de convivência são inscritos na contemporaneidade.

ao emancipar-se da autoridade dos adultos, a criança não foi libertada, e sim sujeita a uma autoridade muito mais terrível e verdadeiramente tirânica, que é a tirania da maioria. Em todo o caso, o resultado foi serem as crianças, por assim dizer, banidas do mundo dos adultos. (Arendt, 2007, p. 230)

Embora suas reflexões digam respeito a um acontecimento que envolve o campo da educação no contexto da sociedade americana na década de 50, ao ressaltar que "a essência da educação é a natalidade", indicando que as crianças, como recém-chegadas a um mundo preexistente precisam ser acolhidas, e a tarefa da educação seria justamente ajudá-las a introduzir-se no mundo e estimular sua participação no mundo comum de realizações simbólicas e materiais, encontramos uma chave de leitura importante para pensar a cidade como uma experiência compartilhada entre adultos e crianças. Todavia, Almeida (2011) sublinha:

O que está em jogo é a própria crença no mundo e na possibilidade de estabelecermos um lugar de convivência que seja humano e humanizante ao mesmo tempo. Não se trata, portanto, de afirmar que o mundo deva ser mantido em seu estado atual, nem de dizer que alguma vez na história houve um mundo ideal, nem que é possível extrair do passado valores e normas que nos instruam sobre como construir esse lugar, mas sim de acreditar que no meio de cacos da tradição, e de um passado sem certez̧a de julgamento, [ênfase no original] houve momentos e experiências que testemunham a possível grandeza desse espaço. (p. 116)

Se "na educação, a responsabilidade pelo mundo assume a forma de autoridade", conforme destacara Arendt (2007, p. 239), a educação na cidade, como um compromisso assumido com o mundo comum, se constituiria em um atributo dos adultos diante das crianças, de modo que elas possam no futuro responsabilizar-se pela fruição do mundo e por sua renovação. Um desafio e tanto para uma sociedade cuja perda da autoridade interage com a nossa atitude em relação ao passado e à busca incessante pelo futuro. Daí porque Arendt (2007) afirma que "a crise da autoridade na educação guarda a mais estreita conexão com a crise da tradição, ou seja, com a crise de nossa atitude face ao âmbito do passado" (p. 243), inspiração 


\section{pro.posições}

$e$-ISSN 1980-6248

http://dx.doi.org/10.1590/1980-6248-2016-0021

essa extraída da experiência romana, em que o passado era considerado uma referência importante para um agir consistente no presente, cuja durabilidade transcende o próprio tempo. Nesse caso, a cidade passa a ser um lugar de abrigar o mundo e tornar públicas as tradições culturais que formam a herança simbólica de modo que as crianças possam delas participar e renovar o mundo. Arendt (2007) recupera as palavras de Políbio, quando esse diz que educar era simplesmente "fazer-vos ver que sois inteiramente dignos de vossos antepassados" (pp. 244245).

Se a temporalidade que atravessa as sociedades modernas é "a instituição de um presente opaco, sem passado ou futuro, plasmado, petrificado" (Matos, 2009a, p. 73), pensar a cidade como uma experiência pública compartilhada e percebê-la como uma comunidade de sentido, "um lar imortal para seres mortais", requer um outro modo de olhar as crianças e de nos comprometermos com a sua educação na cidade. Isso porque, sob o ponto de vista das lógicas que enredam as cidades contemporâneas, um duplo constrangimento em relação às crianças se estabelece: um que evoca a ruína da cidade como espaço público, preservando as crianças de seus acontecimentos, riscos, imprevisibilidades e memórias, mantendo-as artificialmente em seu próprio mundo, em sua esfera privada; e outro que estabelece formas periciais de autoproteção das crianças, excluindo-as da "arte do com-viver" para a "prática do sobreviver", caminho que não implica em corresponsabilidades públicas, mas um modo de fazer as crianças enfrentar por si mesmas as contingências da vida na cidade.

Em ambos os casos, há uma forma peculiar de expulsar as crianças do mundo dos adultos e abandoná-las aos seus próprios recursos, já que o objetivo é instruí-las na arte de viver e não ensiná-las como o mundo é. Ensinar as crianças como um mundo é requer um esforço contínuo de compartilhar com elas as heranças e a memória do passado como suporte de criação de uma cultura pública na cidade. Sem tais prerrogativas, não há chance de as crianças que chegam ao mundo se sentirem nele acolhidas. Contudo, Arendt (2007), afirma que "também o mundo necessita de proteção, para que não seja derrubado e destruído pelo assédio do novo que irrompe sobre ele a cada nova geração" (p. 235).

Tanto a manutenção artificial das crianças em seu próprio mundo quanto a fabricação de dispositivos que as instruam na "arte de sobreviver" na cidade constituem artifícios da modernidade para fazê-las independentes, autônomas. Tais tentativas não só interditam os espaços da cidade de serem testemunhas de trocas intergeracionais, mas desmobilizam a 


\section{pro.posıções}

$e$-ISSN 1980-6248

http://dx.doi.org/10.1590/1980-6248-2016-0021

expectativa de criação de outros suportes materiais e simbólicos que culminariam com o estabelecimento de reciprocidades entre adultos e crianças na cidade.

Se o olhar de "espanto" foi suplantado pelo olhar de "perplexidade" com a modernidade, responsabilizarmos pelo mundo - entendido como algo que compartilhamos com as crianças-, narrar nossas experiências e introduzir as crianças à memória da comunidade, parece ser um artifício importante para a criação da cidade em uma morada agradável e em um espaço comum de valores partilhados entre adultos e crianças.

A familiarização da criança com o mundo requer outros tipos de vínculos que vão além de sua preparação às possíveis ameaças que assaltam a sua segurança e a sua liberdade na cidade. Isso, por sua vez, exige outra forma de fazer experiência na cidade em companhia delas, o que certamente pressupõe um compromisso e uma responsabilidade de educá-las em um mundo preexistente, sem aqueles ensinamentos que terminam por transformá-las no mais novo transeunte da cidade, fixando-as na própria individualização de seus atos e lançando-as aos seus próprios interesses e sobrevivência. Parece estar aí um modo peculiar de acolher e educar a criança na cidade, ajudando-a a compreender o mundo como ele é, e não apenas ensina-lhe como o mundo deve ser.

\section{Criança: uma "estrangeira" a ser acolhida na cidade - considerações finais}

Olgária Matos (2010), ao recobrar uma belíssima passagem do poema “Odisseia” de Homero, destaca uma cena quando Ulisses, ao chegar a Ítaca, é recebido por Eumeu, um antigo guardador de porcos que não reconhece mais seu senhor porque a deusa Athena o havia transformado em ancião, mas mesmo assim Eumeu o acolhe em sua tenda dizendo: "vem, segue-me; entremos em minha tenda; desejo que de alimentos e vinho te sacies, depois tu me dirás de onde vens e os males que teu coração suportou” (Matos, 2010, p. 38).

Essa acolhida incondicional de Eumeu a um "estrangeiro que chega sem aviso", representa uma das virtudes públicas mais caras aos gregos que é a hospitalidade, uma atitude de humanidade para com aquele que chega de forma imprevista e inesperada. Na hospitalidade, ressalta Matos (2010, p. 38), "não se trata de nomos - hábito com força de lei humana -, mas de 


\section{pro.posıções}

e-ISSN 1980-6248

http://dx.doi.org/10.1590/1980-6248-2016-0021

uma lei divina, lei moral'[ênfase no original]. Incondicionalmente aberta àquele que chega sem avisar, a hospitalidade é da ordem do puro dom (Matos, 2009a, p. 68).

Tal como a amizade, a concórdia e a responsabilidade, consideradas virtudes públicas para os gregos, a hospitalidade era uma chave para a vida social; uma atitude de compaixão para com o desconhecido, com aquele que acabara de chegar inesperadamente. Como "lei moral", a hospitalidade não se subordina a nenhuma conveniência, mas impele a uma atitude de compaixão, pois estrangeiros e não estrangeiros, todos, participavam de uma mesma humanidade.

Essas passagens evidenciadas por Matos (2009a, 2010) nos fazem interrogar em que medida estamos acolhendo as crianças no mundo e compartilhando com elas um mundo comum na cidade. Se a hospitalidade representa um vínculo de proteção com aquele que precisa ser acolhido, isso significa que há mais do que uma disposição de reconhecer o outro em suas necessidades físicas, pois "na hospitalidade se estabelece um código de convivência tão importante e benéfico para a comunidade quanto para o desenvolvimento do ser humano" (Freitas, 2007, p. 63). Tal como o estrangeiro acolhido, acolher as crianças na cidade é empreender um modo de com-viver e bem-viver que ultrapassa as condicionalidades da simples ajuda e da tutela dos adultos, já que a hospitalidade é um ato de humanidade nos momentos de infortúnio para com aquele que chega, e não de barganha e proteção desmedida. A hospitalidade se coloca numa relação de alteridade, pois o outro, igual a mim, necessita ser reconhecido e acolhido.

Em uma sociedade cujas ordens das urgências despontencializam objetivos e significações partilhadas, a gratuidade da acolhida é subvertida por formas tipificadas de atendimento às necessidades das crianças, quando essas são lançadas a um mundo cujas garantias da hospitalidade e da amizade são condenadas ao esquecimento. O cuidado se converte em obrigações que não geram responsabilidades dos adultos sobre as crianças, mas uma espécie de conforto em relação aos efeitos da sua proteção e provisão, como se a elas bastasse o derradeiro esforço para a manutenção da vida, traduzido pela defesa de sua proteção e provisão. As crianças estão mais próximas aos adultos, ao menos se entretêm com os mesmos serviços disponíveis pela sociedade de consumo, mas são pouco convidadas a compartilhar um mundo comum com eles. Ascenderam a uma existência mais autônoma, mas isso implicou em outras formas de enclausuramento e evitamento dos espaços públicos. 


\section{pro.posıções}

$e$-ISSN 1980-6248

http://dx.doi.org/10.1590/1980-6248-2016-0021

A “crise na educação", descrita por Arendt (2007), parece transpor-se à crise na cidade, quando a exagerada preocupação com a segurança, a proteção e a emancipação das crianças subtraem as possibilidades de uma coexistência compartilhada com os adultos. Contudo, destaca Almeida (2011), o comum para Arendt "não é, portanto, constituído à custa das singularidades, mas a partir delas" (p. 99), por isso que a existência de um espaço público depende, fundamentalmente, da pluralidade, ou seja, do estar-em-companhia. Cabe aqui retomar o conceito de "amor mundi" de Arendt, pois ele evoca uma responsabilidade em relação ao mundo e ao público, não como um valor privado, mas como um conjunto de tradições e valores simbólicos e materiais a ser transmitido às novas gerações, de modo que, "como ser novo no mundo", as crianças não sejam separadas da comunidade adulta.

Vários tipos de cerceamento são inventados com o objetivo de "tirar as crianças das ruas". O conhecido slogan "lugar de criança é na escola" termina por instituir a escola como locus exclusivo de educação, como se as ruas, espaço considerado suspeito e ameaçador, fosse uma prerrogativa e um "direito" somente dos adultos. Se a "cidade educadora" representa um avanço para se pensar uma convivência mais digna e humana para todos, ela não é uma realidade autoevidente de educação, já que a educação exige que aqueles que chegaram ao mundo por primeiro responsabilizem-se coletivamente por ele, proporcionando às futuras gerações uma realidade mais estável e duradoura, ajudando-as a perceber o quanto a experiência dos antepassados pode continuar iluminando o presente, sobretudo num tempo de incertezas e perigos.

Acolher as crianças em sua estrangeiridade pressupõe uma hospitalidade incondicional para com aquele que acabou de chegar em um mundo preexistente, o que significa instaurar outras formas de com-viver e co-habitar, mas, também, romper, com uma temporalidade esvaziada de sentido, potencializando a cidade como espaço público de objetivos e significações partilhada entre adultos e crianças, como uma philia social. Parece estar aí a possibilidade de preservar o mundo da ruína natural do tempo, fazendo com que a permanência de um mundo comum se estenda para além da esfera privada e do presente, constituindo-se em uma referência importante para a cultura pública e para as gerações futuras.

Chamando a atenção para as ameaças constantes da dissolução do mundo como um conjunto de referências a serem compartilhadas, tendo por horizonte um destino comum, Arendt (2011) destaca que "só a existência de um domínio público e a subsequente 


\section{pro.posıções \\ $e$-ISSN 1980-6248}

http://dx.doi.org/10.1590/1980-6248-2016-0021

transformação do mundo em uma comunidade de coisas que reúne os homens e estabelece uma relação entre eles dependem inteiramente da permanência" (p. 67).

A falta de compromisso com o mundo comum reverbera na profunda ausência de responsabilidade dos adultos em relação às crianças que, despojadas de uma experiência compartilhada, continuam prisioneiras da própria existência privada, do "reino da necessidade", a partir do qual não é mais possível criar outras formas de sociabilidades, preso que está ao consumo e à manutenção da vida. Diversamente dessa atitude, acolher a criança estrangeira que chega sem ser convidada e de modo intempestivo, trata-se de romper com a superficialidade dos vínculos humanos, fazendo da cidade um laço afetivo entre crianças e adultos, uma morada digna, um espaço no qual a ação e a palavra de cada um podem ser reconhecidas na construção de uma esfera pública compartilhada. 


\section{pro.posıções}

$e$-ISSN 1980-6248

http://dx.doi.org/10.1590/1980-6248-2016-0021

\section{Referências}

Almeida, V. S. (2011). Educação em Hannah Arendt: entre o mundo deserto e o amor ao mundo. São Paulo, SP: Cortez.

Arendt, H. (1987). Homens em tempos sombrios. São Paulo, SP: Companhia das Letras.

Arendt, H. (2002). O que é política? (3a ed.). Rio de Janeiro, RJ: Bertrand Brasil.

Arendt, H. (2007). Entre o passado e o futuro. São Paulo, SP: Perspectiva.

Arendt, H. (2008). A promessa da política. Rio de Janeiro, RJ: DIFEL.

Arendt, H. (2010). A condição humana. Rio de Janeiro: Forense.

Aristóteles (2009). Ética a Nicômaco (A. de C. Caeiro, trad.). São Paulo, SP: Atlas.

Assy, B. (2004). Faces privadas em espaços públicos: por uma ética da responsabilidade. In H.

Arendt, Responsabilidade e julgamento (pp.31-60). São Paulo, SP: Companhia das Letras.

Assy, B. (2015). Ética, responsabilidade e juízo em Hannah Arendt. São Paulo, SP: Perspectiva.

Bauman, Z. (2000). Em busca da política. Rio de Janeiro, RJ: Jorge Zahar.

Benjamin, W. (2012). Rua de mão única (Obras Escolhidas, vol.2, 6a ed. revista). São Paulo, SP: Brasiliense.

Brayner, F. (2008). Educação e republicanismo: experimentos arendtianos para uma educação melhor. Brasília, DF: Líber Livro.

Carvalho, J. S. F. (2013). Reflexões sobre educação, formação e esfera pública. Porto Alegre, RS: Penso.

Dany-Dufour, R. (2005). A arte de reduzir as cabeças: sobre a nova servidão na sociedade ultraliberal. Rio de Janeiro: Companhia de Freud.

Freitas, M. S. (2007). Sobre a ética em Homero. Dissertação de Mestrado, Programa de PósGraduação em Filosofa e Ciências Sociais, Universidade Federal do Rio de Janeiro, Rio de Janeiro. 


\section{pro.posıções}

$e$-ISSN 1980-6248

http://dx.doi.org/10.1590/1980-6248-2016-0021

Gomes, R. C. (2008). Todas as cidades, a cidade: literatura e experiência urbana. Rio de Janeiro, RJ: Rocco.

Kuster, E., \& Pechman, R. M. (2007). Da ordem. Da cidade. Da literatura: personagens à beira do "ruim do mundo". Sociedade e Estado, 22(3), 593-620. doi: 10.1590/S010269922007000300005.

Matos, O. (2006). Discretas esperanças: reflexões filosóficas sobre o mundo contemporâneo. São Paulo, SP: Nova Alexandria.

Matos, O. (2009a). Contemporaneidades. São Paulo, SP: Lazuli/Companhia Editora Nacional.

Matos, O. (2009b). Walter Benjamin: polis grega, metrópolis modernas. In S. J. Souza, \& S. Kramer (Orgs.), Política, cidade, educação: itinerários de Walter Benjamin. Rio de Janeiro, RJ: Contraponto: Ed. PUC - Rio.

Matos, O. (2010). Pedras e utopias: do cosmopolitismo à hospitalidade. In D. Milan, \& O. Matos (Orgs.), Gemas da terra: imaginação estética e hospitalidade (pp. 25-44). São Paulo, SP: Edições SESC.

Ortega, F. (2002). Genealogias da amizade. São Paulo, SP: Iluminuras.

Sartre, J.-P. (2002). Crítica da razão dialética: precedido por questões de método. Rio de Janeiro, RJ: DP\&A.

Sennett, R. (1988). O declínio do homem público: as tiranias da intimidade. São Paulo, SP: Companhia das Letras.

Submetido à avaliação em 16 de março de 2016; revisado em 1 de julbo de 2016; aceito para publicação em 11 de outubro de 2016. 